\title{
Adherence to Multiple Sclerosis Disease- Modifying Therapies in Ontario is Low
}

\author{
Janice Wong, Tara Gomes, Muhammad Mamdani, Michael Manno, \\ Paul W. O’Connor
}

\begin{abstract}
Background/Objective: Differences in patient adherence to various disease-modifying drugs (DMDs) in the treatment of multiple sclerosis (MS) are not well understood. The goal of this study was to evaluate adherence of adult MS patients in Ontario with public drug plan coverage to various DMDs: intramuscular interferon beta-1a (i.m. IFN $\beta-1 \mathrm{a}$, Avonex), subcutaneous interferon beta-1a (s.c. IFN $\beta-1 \mathrm{a}$, Rebif), subcutaneous interferon beta-1b (IFN $\beta-1 b$, Betaseron) or glatiramer acetate (Copaxone). Methods: In this retrospective cohort study, Ontario Public Drug Plan beneficiaries aged 15 or older who were newly treated with i.m. IFN $\beta$-1a, s.c. IFN $\beta$-1a, IFN $\beta$-1b or glatiramer acetate between April 2006 and March 2008 were followed forward until treatment discontinuation, switch to another DMD or a maximum two year follow-up period. Cumulative persistence rates were analyzed by the Kaplan-Meier method. The proportion of patients reaching the study endpoints after the two year follow-up period was also calculated. Results: Cumulative persistence rates for all four DMDs were similar over time ( $\mathrm{p}=0.80)$, ranging from 73.6-79.1\% at six months, 59.1-63.1\% at one year and 41.5-47.4\% at two years. After two years, the proportion of patients who had discontinued treatment, switched to another DMD or died was similar among DMDs ( $\mathrm{p}=0.79$, Fisher's exact test). Switching between DMD types was low and occurred in 3.4-6.5\% of new DMD users. Conclusions: Adherence to DMDs in adult MS patients in Ontario is poor, which is consistent with previously reported adherence rates to MS DMDs in other regions. No significant differences in adherence exist between the DMDs evaluated in this study.
\end{abstract}

RÉSUMÉ: La fidélité aux traitements de fond dans la sclérose en plaques est faible en Ontario. Contexte et objectif : Les différences dans la fidélité des patients aux différents traitements de fond (TF) utilisés dans le traitement de la sclérose en plaques (SP) sont mal comprises. Le but de cette étude était d'évaluer la fidélité au traitement chez des patients adultes atteints de SP en Ontario où le plan publique d'assurance-médicament couvre différents TF : l'interféron bêta-1a par voie intramusculaire (IFN $\beta$-1a i.m., Avonex), l'interféron bêta-1a par voie sous-cutanée (IFN $\beta$-1a s.c., Rebif), l'interféron bêta-1b par voie sous-cutanée (IFN $\beta-1 \mathrm{~b}$, Betaseron) et l'acétate de glatiramère (Copaxone). Méthode : Il s'agit d'une étude rétrospective de cohorte portant sur les bénéficiaires du Ontario Public Drug Plan, âgés de 15 ans et plus, qui ont commencé un traitement par l'IFN $\beta$-1a i.m., l'IFN $\beta$ 1a s.c., l'IFN $\beta$-1b ou l'acétate de glatiramère entre avril 2006 et mars 2008 et qui ont été suivis jusqu'à l'arrêt du traitement, la substitution d'un autre TF ou pendant une période maximum de deux ans. Les taux de persistance cumulatifs ont été analysés par la méthode de Kaplan-Meier. La proportion de patients qui rencontraient les critères d'évaluation de l'étude après deux ans de suivi a également été calculée. Résultats : Les taux de persistance cumulatifs pour les $4 \mathrm{TF}$ étaient similaires au cours de la durée de l'étude $(\mathrm{p}=0,80)$, allant de $73,6 \%$ à $79,1 \%$ après 6 mois, 59,1\% à $63,1 \%$ après 1 an et $41,5 \%$ à 47,4\% après 2 ans. La proportion des patients qui avaient cessé le traitement, poursuivi le traitement avec un autre TF ou étaient décédés était similaire après 2 ans, quelque soit le TF ( $\mathrm{p}=0,79$; Fisher's exact test). Le taux de substitution d'un type de TF par un autre était faible, soit de $3,4 \%$ à $6,5 \%$ chez les utilisateurs de TF. Conclusion : La fidélité aux TF chez les patients adultes atteints de SP en Ontario est faible et elle est comparable aux taux de fidélité au traitement rapportés antérieurement dans d'autres régions. Nous n'avons pas constaté de différence significative dans la fidélité au traitement pour les TF évalués dans cette étude.

Can. J. Neurol. Sci. 2011; 38: 429-433

The use and costs of disease-modifying drugs (DMDs) for the treatment of multiple sclerosis (MS) have risen between 2002 and 2007 across Canada, ${ }^{1}$ underscoring the importance of knowing the actual extent of patient adherence to these medications. Adherence improves both patient outcomes and utilization of health care resources in the management of MS. In one study, non-pharmaceutical medical costs were higher for patients who switch or discontinue DMDs compared to those who persist. ${ }^{2}$ In another study, adherence to interferon beta was associated with a reduced risk of relapse in multiple sclerosis, as well as a decreased risk of emergency room visits and inpatient admissions. ${ }^{3}$ Therefore, non-adherence to DMDs has potentially serious personal and societal implications.
Large-scale studies have been conducted in the United States, Canada, Spain, Sweden, Italy and Brazil on patient adherence to MS DMDS, with several studies reporting various reasons for

\footnotetext{
From the Division of Neurology (JW, PWO), Department of Medicine (MuM), Keenan Research Centre of the Li Ka-Shing Knowledge Institute (MuM), St. Michael's Hospital, The Leslie Dan Faculty of Pharmacy (TG, MM); Institute for Clinical Evaluative Sciences (TG, MuM, MM), Department of Health Policy, Management and Evaluation (MuM), University of Toronto, Toronto, Ontario, Canada; King Saud University (MuM), Riyadh, Saudi Arabia.

Received September 21, 2010. Final Revisions Submitted November 23, 2010. Correspondence to: Paul O'Connor, 30 Bond Street, Suite 3-007 Shuter Wing, St. Michael's Hospital, Toronto, Ontario, M5B 1W8, Canada.
} 
non-adherence. ${ }^{4-10}$ Studies in Sweden, Spain and Italy found that the most commonly reported reasons for switch or discontinuation were perceived lack of efficacy and side effects. ${ }^{7-9}$ In a study on MS clinic patients in British Columbia, Canada, the most common reason for non-adherence to interferon beta was also perceived lack of efficacy. ${ }^{10} \mathrm{~A}$ Brazilian study found that medical decisions were the most common reason for discontinuation from glatiramer acetate. ${ }^{5}$ A study in the US cited 'simply forgetting' as the most common reason for non-adherence to DMDs. ${ }^{11}$ Variations in characteristics of DMD adherence among countries are not surprising, as DMDs are administered under distinct health care systems. For instance, costs of DMDs were covered by the tax system in Sweden $^{7}$ and by commercial insurance in the US. ${ }^{4}$

To our knowledge, large-scale studies on patient adherence to MS DMDs have not yet been conducted in Ontario, where a proportion of MS DMDs are publicly covered. Furthermore, it is not well understood whether there are differences in adherence to various MS DMDs, given that each DMD tends to be marketed as having superior efficacy, side effects or convenience. The objective of this study was to examine and compare adherence to various DMDs in a diverse population of adult MS patients in Ontario who have public drug plan coverage.

\section{Methods}

A retrospective cohort study was conducted of Ontario Public Drug Plan beneficiaries aged 15 or older who were newly treated with a DMD (intramuscular interferon beta-1a (i.m. IFN $\beta$-1a, Avonex), subcutaneous interferon beta-1a (s.c. IFN $\beta$-1a, Rebif), subcutaneous interferon beta-1b (IFN $\beta-1 b$, Betaseron), or glatiramer acetate (Copaxone)) between April 2006 and March 2008. In Ontario, residents are eligible for coverage through the
Ontario Public Drug Plan if they are over the age of 65, are unemployed or disabled, have high prescription drug costs in relation to their net household income, receive home care or reside in a long-term facility.

Prescriptions for DMDs were identified using the Ontario Public Drug Plan Database (ODB) and the Registered Persons Database was used to obtain demographic information on included patients. Neighbourhood income quintiles were used as proxies for socio-economic status, where an income quintile of one represented the $20 \%$ of the population with the lowest income, while five represented the $20 \%$ with the highest income. The four DMD groups were compared using F-test for age, Fisher's Exact test for residence in long-term care and Pearson Chi-square for gender and income quintile. A 0.05 level of significance was used for all statistical tests.

The ODB contains detailed information on drug name, number of days supplied and dispensing date for all prescription medications dispensed to Ontario residents eligible for coverage. New users of DMDs were defined as patients who did not claim a DMD prescription in the year prior to their first DMD claim documented in the database over the study period. The cohort entry date was defined as the date of the first such prescription. The continual persistence, adherence and treatment switch rates were measured and compared among four DMDs. For each patient in the cohort, we identified persistence on DMD therapy using an algorithm beginning on the cohort entry date. Persistence was defined as having received a refill for the same DMD within 120 days of the previous prescription. Patients were followed forward to the first of: treatment discontinuation, switch to another DMD or a maximum two year follow-up period. Time to discontinuation (either strict discontinuation or switch to another DMD therapy) was analyzed with the Kaplan-

Table 1: Baseline characteristics of new DMD users

\begin{tabular}{|c|c|c|c|c|c|}
\hline Variable & $\begin{array}{c}\text { i.m. IFN } \beta-1 a \\
(n=186)\end{array}$ & $\begin{array}{c}\text { s.c. IFN } \beta-1 \mathrm{a} \\
(\mathrm{n}=215)\end{array}$ & $\begin{array}{c}\text { IFN } \beta-1 b \\
(n=106)\end{array}$ & $\begin{array}{c}\text { Glatiramer } \\
\text { acetate }(n=175)\end{array}$ & $\begin{array}{c}\text { P-value for } \\
\text { differences } \\
\text { between DMD } \\
\text { groups }\end{array}$ \\
\hline Age (mean, SD) & $38.0(11.0)$ & $37.5(11.4)$ & $39.4(11.6)$ & $37.7(10.6)$ & $0.55^{*}$ \\
\hline Gender (\% Female) & 68.3 & 72.6 & 65.1 & 79.4 & $0.04 * *$ \\
\hline Residence in long term care & $<=5(0.5 \%)$ & $<=5(0.5 \%)$ & $0(0 \%)$ & $<=5(0.6 \%)$ & $0.99 * * *$ \\
\hline Income Quintile & & & & & $0.37 * *$ \\
\hline 1: Lowest income quintile & $51(27.4 \%)$ & $44(20.5 \%)$ & $17(16.0 \%)$ & $38(21.7 \%)$ & \\
\hline 2 & $39(21.0 \%)$ & $36(16.7 \%)$ & $23(21.7 \%)$ & $32(18.3 \%)$ & \\
\hline 3 & $32(17.2 \%)$ & $49(22.8 \%)$ & $31(29.3 \%)$ & $44(25.1 \%)$ & \\
\hline 4 & $34(18.3 \%)$ & $51(23.7 \%)$ & $21(19.8 \%)$ & $33(18.9 \%)$ & \\
\hline 5: Highest income quintile & $29(15.6 \%)$ & $35(16.3 \%)$ & $14(13.2 \%)$ & $27(15.4 \%)$ & \\
\hline Missing & $<=5(0.5 \%)$ & $0(0 \%)$ & $0(0 \%)$ & $<=5(0.6 \%)$ & \\
\hline
\end{tabular}

*F-test; **Pearson Chi-square; ***Fisher's Exact test 


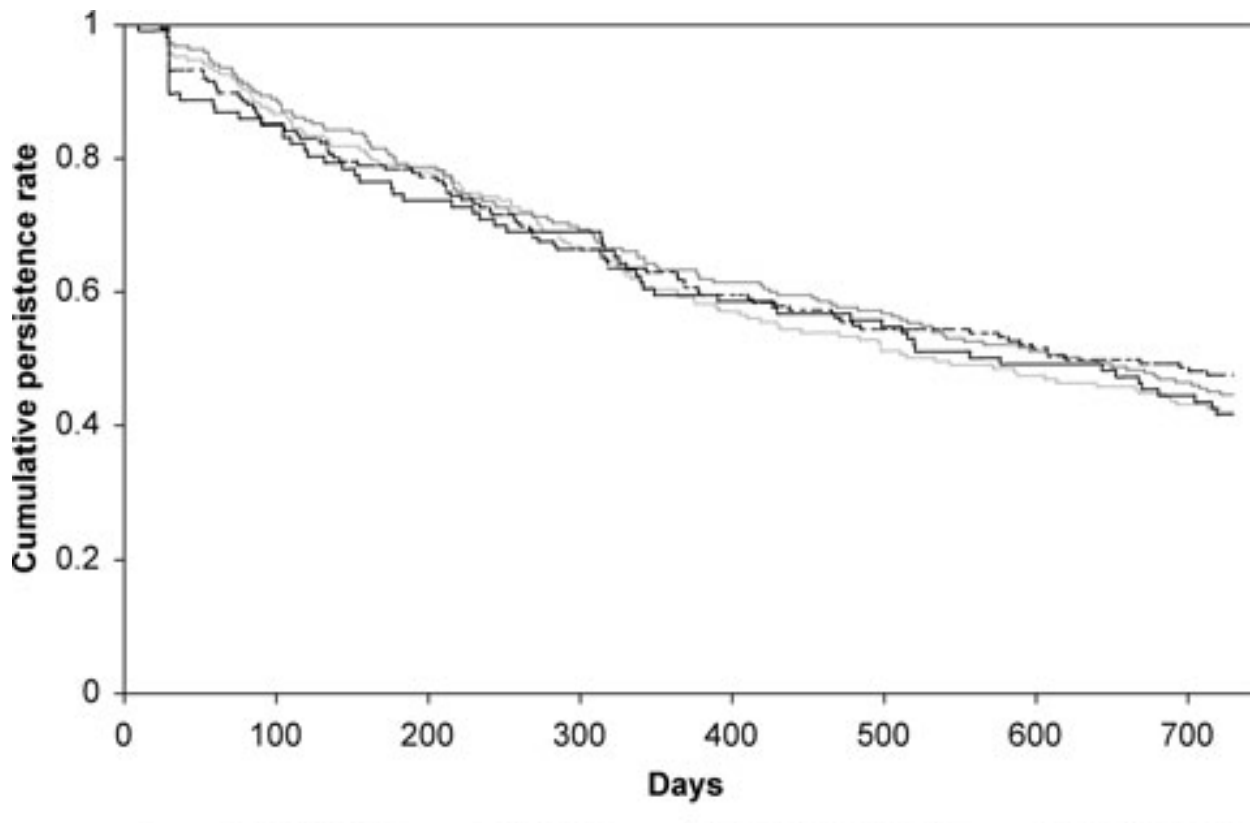

i.m. IFNb-1a —IFNb-1b -...... Glatiramer acetate — s.c. IFNb-1a

Figure: Time to discontinuation of DMD or switch to another DMD, stratified by drug type. Cumulative persistence rates are graphed against time for a cohort of adult multiple sclerosis patients with public drug plan coverage in Ontario who began new DMD use from April 2006 to March 2008. Discontinuation includes both strict discontinuation or switch to another DMD therapy. Cumulative persistence rates against time are stratified by type of DMD: i.m. IFNb-1a (Avonex), s.c.IFNb-1a (Rebif), IFNb-1b (Betaseron), glatiramer acetate (Copaxone).

Meier method, censoring on all other endpoints. The cumulative persistence rate (percentage of patients persisting on initial DMD therapy) against time since cohort entry was graphed, and the Log-Rank test was used to test for equality differences in persistence between DMDs. In a sensitivity analysis, time to discontinuation defined as strict discontinuation alone was evaluated with the same method. The proportion of patients reaching each of the study endpoints after the two year followup period was also calculated.

\section{RESULTS}

Over the two year study period, we identified 682 patients who were newly dispensed a DMD. Among these cohort participants, $186(27.3 \%)$ were newly prescribed i.m. IFN $\beta-1 \mathrm{a}$, $215(31.5 \%)$ were newly prescribed s.c. IFN $\beta-1 \mathrm{a}, 106(15.5 \%)$ were newly prescribed IFN $\beta-1 b$ and 175 (25.6\%) were newly prescribed glatiramer acetate. Baseline characteristics of new DMD users are summarized in Table 1. All demographic characteristics of the four DMD groups were similar, with the exception of gender $(p=0.04)$. The cumulative persistence rates for i.m. IFN $\beta$-1a, s.c. IFN $\beta-1 \mathrm{a}$, IFN $\beta-1 \mathrm{~b}$ and glatiramer acetate were similar over two years $(\mathrm{p}=0.80)$ (Figure). Cumulative persistence ranged from $73.6-79.1 \%$ at six months, 59.1-63.1\% at one year, and $41.5-47.4 \%$ at two years. Defining discontinuation as strict discontinuation alone in analysis of cumulative persistence did not substantially change these results (data not shown).

During the two year follow-up, the proportion of all patients who were continually adherent to DMD therapy, and the proportion of patients who completely discontinued DMD therapy were similar among the four DMD types, with less than half of patients $(\mathrm{N}=300,44.0 \%)$ continually adherent (Table 2). Overall, the proportion of patients who had discontinued treatment or switched to another DMD did not differ significantly among DMDs ( $\mathrm{p}=0.79$, Fisher's exact test). Less than five patients died during the two year period. Switching between DMDs occurred infrequently, and most switches were from i.m. IFN $\beta-1 a$, s.c. IFN $\beta-1 a$ or $\operatorname{IFN} \beta-1 b$ to glatiramer acetate (Table 3 ).

\section{DiscusSION}

Continued adherence rates for i.m. IFN $\beta-1 \mathrm{a}$, s.c. IFN $\beta-1 \mathrm{a}$, IFN $\beta-1 b$ and glatiramer acetate were low and comparable with adherence rates previously reported in Canada and other countries. In British Columbia, only $61 \%$ of MS clinic patients who were prescribed interferon beta and followed over three years remained continually on the therapy. ${ }^{10} \mathrm{~A}$ study in Italy reported that $46 \%$ of patients with relapsing-remitting MS discontinued interferon-beta therapy within four years. ${ }^{9}$ In Sweden, $69 \%$ of patients stopped or switched interferon beta therapy within three years. ${ }^{7}$ One study in the US found that $43 \%$ of new DMD users with relapsing-remitting MS were nonpersistent with medications by 14 months. ${ }^{6}$ Another large study in the United States reported low rates of DMD persistence at 18 months, with significant variation between DMD types. ${ }^{4}$ In this US-based study, IFN $\beta-1 \mathrm{~b}$ had the highest switch and discontinuation rates, while glatiramer acetate had the lowest switch rate and i.m IFN $\beta$-1a had the lowest discontinuation 
Table 2: Adherence to DMDs over two year follow-up period

\begin{tabular}{lcccccc}
\hline \multicolumn{1}{c}{ DMD } & \multicolumn{2}{c}{ Continued adherence } & \multicolumn{2}{c}{ Discontinuation } & \multicolumn{2}{c}{ Switch to other DMD } \\
& $\mathbf{N}$ & $\mathbf{\%}$ & $\mathbf{N}$ & $\mathbf{\%}$ & $\mathbf{N}$ & $\mathbf{\%}$ \\
i.m. IFN $\beta-1 \mathrm{a}$ & 78 & 41.9 & 98 & 52.7 & 10 & 5.4 \\
s.c. IFN $\beta-1 \mathrm{a}$ & 95 & 44.2 & 105 & 48.8 & 14 & 6.5 \\
IFN $\beta-1 \mathrm{~b}$ & 44 & 41.5 & 58 & 54.7 & $<=5$ & 3.8 \\
Glatiramer acetate & 83 & 47.4 & 86 & 49.1 & 6 & 3.4 \\
\hline
\end{tabular}

rate. ${ }^{4}$ In contrast, we did not observe differences in persistence and rates of discontinuation or switching between various MS DMDs, despite their different efficacies, side effects and costs.

Patient adherence to medications in other chronic diseases is also low. For example, adherence to statins was $38.9 \%$ at one year. ${ }^{12}$ For bisphosphonates, persistence was $75.8 \%, 52.1 \%$ and $40.6 \%$ at one, three and five years, respectively. ${ }^{13}$ Persistence to anti-hypertensive medications was $75 \%$ at six months and $55 \%$ in three years. ${ }^{14}$ If compliance to medications were improved, there could be differential cost impacts: drug support program costs may increase, while system-wide medical care costs could decrease due to the health benefits gained by sustained use of medications. For MS DMDs, overall total costs could actually increase with improved adherence, given the high prices of these therapies.

Several limitations to our study merit emphasis. First, most patients included in our study were receiving drug coverage under the Trillium Drug Program, which is intended for Ontario residents with high prescription drug costs in relation to their net household income. Unfortunately, there is no accurate estimate available for the proportion of MS patients in Ontario under the Trillium Drug Program. Furthermore, any patient who lost eligibility during the two year follow-up period would appear to have discontinued their therapy, when in fact their drug use was simply no longer documented. However, due to the high cost of these drugs, loss of eligibility is not expected to be a frequent occurrence. If loss of eligibility occurred, the persistence and adherence rates calculated in our study would tend to be slight underestimations of thru adherence rates in this population.

Secondly, our study used data from Ontario residents with public drug plan coverage. Consequently, our study excluded Ontario residents who did not meet eligibility criteria for public drug plan coverage, including the criteria of socio-economic status and age. United States based studies on MS drug adherence reported that household income ${ }^{6}$ or employment status $^{11}$ was not significantly associated with MS drug adherence. Older age was associated with increased adherence. ${ }^{6,11}$ While our Ontario-based study may not be readily generalizable to other regions, our results are reassuringly consistent with previously reported adherence rates to MS DMDs.

\section{Conclusions}

Our study concludes that the persistent use of i.m. IFN $\beta$-1a, s.c. IFN $\beta$-1a, IFN $\beta-1 \mathrm{~b}$ and glatiramer acetate by adult multiple sclerosis patients in Ontario with public drug plan coverage decreased substantially over time. Adherence rates calculated in our study are consistent with previously reported adherence rates to MS DMDs, and to medications in other chronic diseases. Whether the advent of oral therapies in MS will change this adherence picture is unknown. As such therapies are currently close to approval in Canada, the United States and Europe, it will not be long before information on adherence to oral therapies in MS becomes available. What does seem clear is that irrespective

Table 3: Switching patterns between DMDs over two year follow-up period

\begin{tabular}{|c|c|c|c|c|c|}
\hline \multirow[t]{2}{*}{ Initial DMD } & \multirow{2}{*}{$\begin{array}{c}\text { Total New } \\
\text { Users who } \\
\text { Switched } \\
\text { Treatment }\end{array}$} & \multicolumn{4}{|c|}{ Drug Switched to (N(\%)) } \\
\hline & & i.m. IFN $\beta-1 \mathrm{a}$ & IFN $\beta-1 b$ & s.c. IFN $\beta-1 \mathrm{a}$ & $\begin{array}{c}\text { Glatiramer } \\
\text { acetate }\end{array}$ \\
\hline i.m. IFN $\beta-1 \mathrm{a}$ & 10 & & $<=5(10 \%)$ & $<=5(20 \%)$ & $7(70 \%)$ \\
\hline IFN $\beta-1 b$ & $<=5$ & $<=5(25 \%)$ & & $0(0 \%)$ & $<=5(75 \%)$ \\
\hline s.c. IFN $\beta-1 \mathrm{a}$ & 14 & $<=5(7.1 \%)$ & $<=5(14.3 \%)$ & & $11(78.6 \%)$ \\
\hline Glatiramer acetate & 6 & $<=5(16.7 \%)$ & $<=5(16.7 \%)$ & $<=5(66.7 \%)$ & \\
\hline
\end{tabular}


of the different types of DMDs used or their varying frequency of injection, there is no basis to believe that adherence to these medications in practice differs substantially.

\section{ACKNOWLEDGEMENTS}

This study was supported by a grant from the Ontario Ministry of Health and Long-Term Care (MOHLTC) Drug Innovation Fund and the Institute for Clinical Evaluative Sciences (ICES), a non-profit research institute sponsored by the Ontario MOHLTC. The opinions, results and conclusions reported in this paper are those of the authors and are independent from the funding sources. No endorsement by ICES or the Ontario MOHLTC is intended or should be inferred. We thank Brogan Inc., Ottawa for use of their Drug Product and Therapeutic Class Database.

\section{CONFLICT OF INTEREST/DiscLOSURE}

Paul O'Connor has received consulting fees and/or research support for MS trials from Abbott, Bayer, Biogen Idec, BioMS, Cognosci, Daiichi Sankyo, EMD Serono, Genentech, Genmab, Novartis, Roche, Sanofi Aventis, Teva, Warburg Pincus and Wyeth.

\section{REFERENCES}

1. Rotstein DL, Mamdani M, O'Connor PW. Increasing use of disease modifying drugs for MS in Canada. Can J Neurol Sci. 2010;37 (3):383-8.

2. Reynolds MW, Stephen R, Seaman C, Rajagopalan K. Healthcare resource utilization following switch or discontinuation in multiple sclerosis patients on disease modifying drugs. J Med Econ. 2010;13(1):90-8.

3. Steinberg SC, Faris RJ, Chang CF, Chan A, Tankersley MA. Impact of adherence to interferons in the treatment of multiple sclerosis: a non-experimental, retrospective, cohort study. Clin Drug Investig. 2010;30(2):89-100.
4. Reynolds MW, Stephen R, Seaman C, Rajagopalan K. Persistence and adherence to disease modifying drugs among patients with multiple sclerosis. Curr Med Res Opin. 2010;26(3):663-74.

5. de Oliveira Tde M, Fiore AP, Fragoso YD. Adherence to glatiramer acetate treatment for multiple sclerosis: the Brazilian experience. Patient Prefer Adherence. 2008;2:41-6.

6. Lafata JE, Cerghet M, Dobie E, et al. Measuring adherence and persistence to disease-modifying agents among patients with relapsing remitting multiple sclerosis. J Am Pharm Assoc (2003). 2008;48(6):752-7.

7. Cunningham A, Gottberg K, von Koch L, Hillert J. Non-adherence to interferon-beta therapy in Swedish patients with multiple sclerosis. Acta Neurol Scand. 2010;121(3):154-60.

8. Río J, Porcel J, Téllez N, et al. Factors related with treatment adherence to interferon beta and glatiramer acetate therapy in multiple sclerosis. Mult Scler. 2005;11(3):306.

9. Portaccio E, Zipoli V, Siracusa G, Sorbi S, Amato MP. Long-term adherence to interferon beta therapy in relapsing-remitting multiple sclerosis. Eur Neurol. 2008;59(3-4):131-5.

10. Tremlett HL, Oger J. Interrupted therapy: stopping and switching of the beta-interferons prescribed for MS. Neurology. 2003 Aug 26; 61(4):551-4.

11. Treadaway K, Cutter G, Salter A, et al. Factors that influence adherence with disease-modifying therapy in MS. J Neurol. 2009 Apr;256(4):568-76.

12. Vinker S, Shani M, Baevsky T, Elhayany A. Adherence with statins over 8 years in a usual care setting. Am J Manag Care. 2008;14 (6):388-92.

13. Melo M, Qiu F, Sykora K, Juurlink D, Laupacis A, Mamdani M. Persistence with bisphosphonate therapy in older people. J Am Geriatr Soc. 2006;54(6):1015-16.

14. Perreault S, Lamarre D, Blais L, et al. Persistence with treatment in newly treated middle-aged patients with essential hypertension. Ann Pharmacother. 2005;39(9):1401-8. 